\title{
Poststronismo, reforma constitucional y transición democrática. La construcción de una nueva legalidad en Paraguay
}

Poststronism, constitutional reform and democratic transition. The construction of a new legality in Paraguay

\author{
Florencia Prego \\ Universidad de Buenos Aires - IEALC, Argentina \\ prego.florencia@gmail.com
}

\section{ReSUMEN:}

El derrocamiento de Alfredo Stroessner (1989), como corolario de un golpe que se produjo "desde arriba" y desde el interior del mismo régimen, desató una crisis hegemónica con vigencia hasta la actualidad. La propuesta de este trabajo es analizar, desde la perspectiva de la sociología histórica, los mecanismos utilizados tras el fin del régimen autoritario stronista para reconstruir la legalidad y otorgarle al régimen democrático la legitimidad necesaria para reproducir la forma de dominación. En ese sentido, nos abocaremos al análisis de la reforma de la Constitución Nacional (1992), que expresa la pugna imperante entre las fuerzas conservadoras y las fuerzas democráticas en el bloque dominante en Paraguay, en el marco de un contexto regional que favorecía a estas últimas.

Sin embargo, la herencia en el sistema político en general y en la cultura política en particular de elocuentes signos de autoritarismo, la singular naturaleza del Estado paraguayo, como así también las disputas suscitadas en el seno de las clases dominantes, hicieron del tránsito a la democracia un camino largo y sinuoso que, hasta la actualidad, evidencia importantes signos de continuidad respecto al régimen dictatorial depuesto a fines de la década de los ochenta.

La reforma constitucional incorporó una serie de modificaciones de las que nos interesa destacar tres: la prohibición de la reelección presidencial, la incorporación del juicio político y el reemplazo el estado de sitio por el estado de excepción. A partir de estas tres modificaciones o incorporaciones buscaremos analizar y problematizar la construcción de esta nueva legalidad y los condicionamientos que impartieron a la transición y al proceso de consolidación de la democracia en Paraguay.

Palabras Clave: Paraguay, Nueva legalidad, Constitución Nacional, Stronismo, Democracia.

\section{ABSTRACT:}

The overthrow of Alfredo Stroessner (1989), as a corollary to a coup that originated "above" and within the regime itself, unleashed a hegemonic crisis that to this day is still fully valid. The paper aims to analyze, from the perspective of historical sociology, the mechanisms used after the end of the authoritarian stronist regime to reconstruct the legality to give the democratic regime the legitimacy it needed to reproduce the form of domination. To that effect, it will analyze the reform of the National Constitution promoted by Andrés Rodríguez in 1992, since it exposes the prevailing struggle between the conservative forces and the democratic ones within the dominant bloc in Paraguay in a regional context that favored the latter.

The legacy of eloquent signs of authoritarianism in the political system in general and in the political culture in particular, the State's singular nature, and the disputes occurring within the dominant classes made transition to democracy a long and winding road that to this day still shows significant signs of continuity of the authoritarian regime deposed by the late eighties.

The constitutional reform introduced a number of amendments of which we want to highlight three: the prohibition of presidential re-election, the incorporation of the impeachment, and the replacement of the State of siege for the State of exception. Based on these three amendments/incorporations we will attempt to question the limits of the transition and the process of democratization in Paraguay.

KeYwORDS: Paraguay, New legality, National Constitution, Stronism, Democracy.

\section{El aCONTECIMIENTO. ¿UN NUEVo golpe PARLAMENTARio?}

Este trabajo se enmarca en la perspectiva de la sociología histórica, y parte del legado teórico de Braudel (1970) sobre la historia y las duraciones sociales; del reconocimiento de los tiempos múltiples y las contradicciones 
suscitadas entre los mismos. Dado que no existe un solo prisma desde el cual podamos abordar los procesos históricos, advertimos distintas duraciones que se complementan, se acercan, se combinan y se distancian, tomando como premisa para nuestro análisis la pluralidad del tiempo social.

En virtud de lo planteado, partiremos de un acontecimiento que expresó, una vez más, el agotamiento de un tiempo político en Paraguay. Reconociendo la naturaleza "tramposa" que tiene la corta duración para las ciencias sociales, por su carácter "explosivo y detonante, caprichoso y engañoso" (Braudel, 1970), lo enmarcaremos en una dimensión coyuntural que lo supere en cuanto escala temporal: el proceso de transición a la democracia que se inaugura en Paraguay tras el fin del régimen autoritario de Alfredo Stroessner (1989).

La crisis desatada el 31 de marzo del 2017 producto del rechazo generalizado a la enmienda constitucional para habilitar la reelección presidencial -y que fue promovida tanto por sectores del oficialismo como por sectores de la oposición- dejó en evidencia uno de los principales límites que acarrea Paraguay desde, por lo menos, el inicio de la transición a la democracia. Este acontecimiento será el punto de partida para analizar el proceso de reconstrucción de una nueva legalidad bajo el régimen democrático, en perspectiva histórica.

Para comprender el presente histórico paraguayo es necesario recapitular los elementos que desembocaron en el estallido de la crisis señalada. Las aspiraciones presidenciales tanto de candidatos del oficialismo como de la oposición, o más precisamente, de Horacio Cartes (quien al asumir había renunciado a esta posibilidad) y de Fernando Lugo (depuesto como presidente de la Nación tras el juicio político del año 2012), abrió una vez más el debate repercutiendo de forma directa en un escenario social permeable a estas tensiones. La reelección presidencial, como desarrollaremos más adelante, había sido prohibida por la Constitución Nacional de 1992, en un intento por limitar al Poder Ejecutivo e imposibilitar la emergencia de gobiernos autoritarios que se perpetúen en el poder, como fue el caso de Alfredo Stroessner.

Por lo tanto, la posibilidad de consagrar dichas aspiraciones estaba ligada a una modificación constitucional; es decir, se requería de la reconfiguración de un marco jurídico que dote de legalidad esta estrategia. Vale destacar que en Paraguay existen tres mecanismos para modificar la Constitución Nacional:

1. la convocatoria a una Asamblea Nacional Constituyente;

2. la reinterpretación de la Constitución;

3. y la enmienda Constitucional.

Evaluando las condiciones de posibilidad, los tiempos jurídicos y políticos, como así también la correlación de fuerza, los primeros dos mecanismos fueron descartados. La enmienda, en cambio, permitía la modificación parcial de la Constitución sin necesidad de recurrir a una Asamblea y, por lo tanto, se presentaba como el camino de más rápida resolución. Sin embargo, la discusión sobre su legitimidad generó controversias y posturas encontradas entre distintas fracciones políticas como así también en el seno de la sociedad civil, que fueron, cuando menos, subestimadas.

Los acontecimientos que tiñeron las jornadas en que se debatió la enmienda profundizaron el descontento y mermaron la débil legitimidad de origen que tenía la propuesta. Al carecer de mayoría en la Cámara Alta, el oficialismo impulsó un "Senado paralelo" compuesto por 25 miembros parlamentarios, entre los que se encontraban colorados, liberales, oviedistas y lugistas y en el marco de una sesión extraordinaria aprobaron la modificación de los artículos 11, ${ }^{1} 41$ y 117 del reglamento interno y avanzaron en el proyecto de la enmienda.

Para concretar la maniobra, el vicepresidente segundo del Senado, Julio César Velázquez (colorado), usurpó el cargo de presidente al titular, Robert Acevedo (liberal), y actuó de presidente del Senado desde su banca, recibiendo el proyecto y remitiéndolo a comisiones para su dictamen. El reglamento interno establece (art. 37) que los vicepresidentes, en orden de prelación, sustituirán al presidente en casos de muerte, ausencia o impedimento de éste. Velázquez actuó como presidente "de facto" del Senado sin que se registre ninguna de las causales previstas en el reglamento, ya que tanto el presidente Roberto Acevedo (liberal) como el vicepresidente primero Eduardo Petta (independiente) se encontraban presentes en la sala, y la Cámara Alta ni siquiera estaba en sesión ${ }^{2}$ (Quevedo, 2017, párr.3).

Tras hacerse de público conocimiento lo acontecido, se produjeron una serie de manifestaciones públicas de repudio por parte de importantes sectores de la sociedad, como así también de la oposición, materializadas 
en protestas que fueron violentamente reprimidas por las fuerzas de seguridad del Estado. El corolario de la represión fue el asesinato de Rodrigo Quintana, militante del Partido Liberal Radical Auténtico (PLRA), tras la irrupción de la policía en un local partidario.

La Comisión Interamericana de Derechos Humanos ( $\mathrm{CIDH})$ emitió un comunicado de prensa para expresar su preocupación por los hechos de violencia y represión registrados en las protestas e instó al Estado paraguayo a cumplir con sus obligaciones internacionales de respeto y garantía de los derechos humanos; el pleno ejercicio de los derechos a la vida, a la integridad y libertad personal de los manifestantes; y los derechos a la libertad de expresión, reunión pacífica y participación política. ${ }^{3}$ El informe a su vez denunció el asesinato de Quintana e instó al Estado promover una rápida investigación, además de repudiar las más de doscientas (200) detenciones que se llevaron a cabo.

Desde los sectores oficialistas y los medios de comunicación afines salieron a cuestionar la naturaleza de las manifestaciones. El diario La Nación, en su edición impresa, tituló "Una turba atropelló e incendió el Congreso" 4 haciendo referencia a los manifestantes con alusiones tales como "grupo violento", "inadaptados", "enajenada turba", "vándalos". Para Soler (2017) fue un hecho más que simbólico: "las imágenes del Congreso en llamas son, quizás, las que mejor narran el sentido profundo de los sucesos. En rigor, son la metáfora más potente de una sociedad que reclama una nueva clase política y un nuevo pacto social" 5 (párr.8).

Lo sucedido expresa la crisis política que azota a Paraguay desde hace décadas. La discusión en torno a la enmienda y la reelección presidencial profundizó un conflicto político, tanto en la dimensión estatal e institucional como así también societal, reflotando deudas de un pasado no tan reciente.

Debido a la crisis desatada, el presidente Cartes renunció por segunda vez al intento de reelección. La primera fue en octubre de 2016, a través de un comunicado oficial y público, donde solicitó a la banca oficialista de la Cámara Baja rechazar el proyecto de enmienda constitucional debido a la imposibilidad de generar consenso: "las diversas interpretaciones no tienen claridad respecto de la viabilidad legal y, en consecuencia, pueden dividir a la sociedad paraguaya y fracturar al Partido Colorado" ${ }^{6}$

En ésta última oportunidad, Cartes dirigió su renuncia al arzobispo de Asunción: "espero que este gesto de renunciamiento sirva para la profundización del diálogo dirigido al fortalecimiento institucional de la República, en armónica convivencia entre los paraguayos". El Papa Francisco se pronunció y pidió evitar todo tipo de violencia como así también soluciones políticas al conflicto. Días después de la renuncia de Cartes, en la Cámara Baja rechazaron el proyecto de enmienda con setenta y ocho (78) votos a favor (del rechazo) y una (1) abstención. Finalmente, Fernando Lugo también renunció a la reelección.

De esta manera, el estallido de la crisis de marzo de 2017 alteró el tablero electoral y las aspiraciones presidenciales de los principales candidatos reconfigurando la oferta política. Tras las internas que se llevaron a cabo meses después, en diciembre de 2017, quedó compuesta de la siguiente manera: Mario Abdó Benítez, como candidato de la Alianza Nacional Republicana (ANR) - Partido Colorado, y Efraín Alegre del Partido Liberal Radical Auténtico (PRLA) que, en unidad con el Frente Guasú, conformaron la Alianza Ganar.

Es necesario, entonces, explorar la relación entre la estructura y los sujetos (sociales y políticos) intervinientes. Este camino intentaremos desandar para comprender los límites de la democracia paraguaya.

A los efectos de evitar un análisis descriptivo es preciso contemplar las condiciones sociohistóricas que originaron este estallido de violencia política en Paraguay atendiendo a la relación dialéctica entre sujeto y estructura. De acuerdo con la propuesta de Ansaldi y Giordano (2012), la estructura opera como el locus gestante de las condiciones de posibilidad de la violencia, pero no la genera por sí misma.

Es necesario, entonces, explorar la relación entre la estructura y los sujetos (sociales y políticos) intervinientes. Este camino intentaremos desandar para comprender los límites de la democracia paraguaya. 


\section{UN RACCONTO HISTÓRICO DESDE UNA MIRADA DE MEDIANA DURACIÓN}

La producción científica existente parte de un consenso expreso en torno a la particularidad del régimen autoritario de Alfredo Stroessner (1954-1989) en comparación con el resto de las dictaduras del Cono Sur. Elementos comunes que se destacan en los distintos estudios y análisis remiten al rol desempeñado por las Fuerzas Armadas (FFAA), a la preeminencia del Partido Colorado, la naturaleza del Estado y la captura del mismo por parte del partido. En Paraguay y bajo el régimen stronista, las FFAA atravesaron un proceso de "desmilitarización" y el Partido Colorado un proceso de "militarización" combinado con la partidización de las FFAA y del Estado (Rouquié, 1984; Arditi, 1992; Lezcano, 1990; Soler, 2012) plasmando una "unidad granítica" (Abente Brun, 1993; Rodríguez, 1991). De esta manera, la forma de dominación ejercida y los mecanismos de legitimación política sobre los que fundamentaron el ejercicio de poder se constituyeron como las principales variables explicativas para comprender la singularidad del caso paraguayo (Soler, 2012; Ansaldi y Giordano, 2012; Arditi, 1992).

Bajo el régimen stronista no se produjo una ruptura de la institucionalidad heredada como sucedió con las Dictaduras Institucionales de las Fuerzas Armadas del Cono Sur. No se atacó el Parlamento ni la Constitución; y el Partido Colorado devino en el pilar estructurante del régimen autoritario:

(...) el proceso de despolitización de la sociedad también fue ejecutado en el Paraguay, aunque no por el expediente de la supresión formal de las organizaciones, sino por una combinación de monopolio, cooptación y represión que dio por resultado el espectro partidario tal como se conformó a partir del año 1962. El esquema consistía fundamentalmente en consolidar el Partido Colorado como única vía posible de reclamaciones y demandas al Estado, haciéndolo imprescindible en toda actividad social que importara concesión de recursos públicos, o tan solo autorizaciones (Laterza, 1989, p. 372).

El stronismo no sustituyó la legalidad política liberal-democrática ni su legitimidad y apeló a ella como instrumento de legitimación ideológica: el proceso de legitimación-legalización consistía en la toma de la decisión y la ejecución de la acción, y si la conducta se repetía se creaba la norma que la legalizaba y de esa manera actuaba legítimamente por medio de la legalidad. En este sentido, la ley fue utilizada para sostener la voluntad autocrática, lo que fue generando una crisis ética y jurídica (Laterza, 1989).

Partimos del planteo de Soler (2014) quien sostiene que el derrocamiento de Stroessner expresó el agotamiento de una forma de acumulación económica y una forma de dominación política, donde los grupos económicos creados por el régimen stronista a partir de una reorganización de la estructura productiva y financiera, adquirieron autonomía suficiente respecto al régimen político de origen y se amoldaron tanto al nuevo formato democrático como a la metamorfosis del capitalismo mundial. La singularidad del golpe contra Stroessner es que lo llevó adelante una fracción de las FFAA encabezada por el Gral. Andrés Rodríguez; es decir, se produce a partir de una crisis en el bloque dominante, de un desprendimiento de la élite política y militar de la propia dictadura stronista (Soler, 2012). Por lo tanto, es un proceso que se inicia "desde arriba" $\mathrm{y}$ al interior del mismo orden.

Sin embargo, el derrocamiento de Alfredo Stroessner no significó la salida del Partido Colorado de la dirección del Estado ni del gobierno, lo que le permitió constituirse tanto en el partido de la dictadura como en el partido de la transición, y el partido que ganó todas las elecciones hasta el año 2008, con el triunfo de Fernando Lugo. En la génesis misma de la transición está el carácter endeble de la democracia instaurada.

El fin del régimen stronista inauguró una crisis de hegemonía que no ha logrado resolverse hasta la actualidad (Quevedo, 2015; Escobar, 2012). Desde 1989 en adelante se producen una serie de acontecimientos que confirman el grado de tensiones y contradicciones existentes en el seno del bloque dominante. Uno de los casos más relevantes, y que generó mayor conmoción pública, fue el asesinato del vicepresidente Luis María Argaña y la responsabilidad del entonces presidente Raúl Cubas Grau y del Gral. Lino César Oviedo en su muerte. Esto conllevó a la realización de un juicio político contra Cubas Grau precipitando su renuncia al cargo. A su vez, las movilizaciones producidas desembocaron en la masacre del "marzo paraguayo" donde cientos de manifestantes fueron brutalmente reprimidos. Otro acontecimiento 
a señalar es el fallido golpe de Estado en el año 2000 contra el gobierno de Luis Gonzáles Macchi, donde nuevamente aparece la controvertida figura del Gral. Lino César Oviedo. Sin embargo, la situación política y social alcanza su paroxismo con la "masacre de Curuguaty" y el posterior juicio político contra el presidente Fernando Lugo que conlleva a la interrupción de su mandato.

La transición en América Latina en general y en Paraguay en particular, se situó en un contexto histórico donde la democracia devino en la fuente de legitimidad del orden político (Ansaldi y Soler, 2015) y donde las derechas comenzaron a adherir a la democracia representativa. Para estos sectores, que buscan oponerse a la derecha antidemocrática del siglo XX y en particular a la de la década del setenta, el aglutinante fue la defensa de la democracia instrumental como medio para satisfacer los intereses materiales de las burguesías (Giordano, 2014).

El fin del stronismo implicó una puja entre fuerzas autoritarias y conservadoras, y fuerzas que clamaban una apertura democrática, siendo las primeras capaces de condicionar y debilitar el proceso impulsado. La reforma constitucional del año 1992 fue un intento por "democratizar" la política paraguaya y equilibrar los poderes del Estado, -limitando al poder ejecutivo- y desterrar la Constitución de la dictadura (1967):

La Constitución entonces en vigor era susceptible de ser mejorada tomándola como base, sin tener que modificarla radicalmente. En cuanto a la parte dogmática había que ampliar el catálogo de derechos de acuerdo con las normas consagradas en el Derecho Internacional de los Derechos Humanos, y asimismo debían ser ampliadas las garantías consagradas en la Ley Suprema. En cuanto a la parte orgánica, había que eliminar artículos que contenían las disposiciones de carácter autoritario, retocar las atribuciones de los órganos de gobierno ya previstos, y agregar otros órganos de gobierno (Claude, 2012).

De acuerdo al planteo de Claude (2012), pese que el gobierno de Andrés Rodríguez buscaba una reforma parcial de la misma, la carga simbólica que tenía la herencia stronista empujaba a romper con ese pasado dictatorial y, por lo tanto, la eliminación del instrumento supremo de su ordenamiento jurídico era una tarea inmediata y urgente.

\section{LA IMPOSIBILIDAD DE LA REELECCIÓN ¿UNA GARANTÍA PARA EL PROCESO DE DEMOCRATIZACIÓN?}

Uno de los elementos que buscamos destacar y creemos constituye una herramienta clave para pensar, analizar y problematizar los límites de la democracia en Paraguay y la crisis política imperante, radica en la figura de la reelección presidencial. Tras la reforma, el artículo $229^{7}$ de la Constitución Nacional establece sobre la duración del mandato lo siguiente:

El Presidente de la República y el Vicepresidente durarán cinco años improrrogables en el ejercicio de sus funciones, a contar desde el quince de agosto siguiente a las elecciones. No podrán ser reelectos en ningún caso. El Vicepresidente sólo podrá ser electo Presidente para el período posterior, si hubiese cesado en su cargo seis meses antes de los comicios generales. Quien haya ejercido la presidencia por más de doce meses no podrá ser electo Vicepresidente de la República.

Con esta modificación se buscaba establecer un límite jurídico para imposibilitar la repetición de un régimen que se perpetúe en el poder. Sin embargo, no se cuestionó ni tampoco se puso en discusión un factor elemental: la alternancia partidaria. Esto permitió, como decíamos líneas más arriba, que uno de los partidos más tradicionales de Paraguay, como la Alianza Nacional Republicana - Partido Colorado, fuera tanto el partido del régimen autoritario como el del régimen democrático recientemente instaurado.

La no alternancia del partido de gobierno puso en jaque el proceso de consolidación democrática: "En efecto, desde el año 1947 el coloradismo ejerció en forma excluyente el poder político, a través de dictaduras civiles, militares, cívico-militares y en los últimos veinte años -el post stronismo- derrotando electoralmente a sus adversarios" (Camacho, 2012, p. 11). 
Brugnoni (2007) define el fin del stronismo como una alternancia inverosímil: se produce una transición a la democracia, pero sin alternancia política. Esto impregnó y condicionó todo el sistema político generando una lógica de funcionamiento híbrida, que combinó la lógica autoritaria y la lógica democrática; se reproduce así una cultura política autoritaria y de sometimiento que, pese a que no fue inventada por el stronismo, fue profundizada y aprovechada por él, trascendiendo la esfera política para penetrar tanto espacios estatales como societales (Arditi, 1992).

Para poder analizar las matrices que producen el tejido autoritario en la sociedad paraguaya, es preciso sumergir nuestra mirada en una duración mayor que nos permita, en esta combinación mixta de los tiempos sociales, ir más allá de la coyuntura. De esta manera, Arditi (1992) va a distinguir factores explicativos interesantes que incorporamos a este análisis para comprender el presente histórico: el caudillismo y la consecuente relación patrón-cliente que la misma genera, como así también las lealtades primarias sobre las que se construye dicha relación de dominación; el nacionalismo militarista y la idealización de la gesta guerrera como fundadora de la Nación y legitimadora del poder; el despotismo patronal; la estadolatría o el culto al Estado; la intolerancia política y religiosa; y el patriarcado (1992, p. 200). A su vez destaca leyes tácitas como es la ley de mbareté (que permite pasar por alto el ordenamiento en función del respaldo o la protección política que tiene); la ley del ñembotavy (que finge desconocimiento); la ley del gallinero (situación de "guerra de todos contra todos" donde prima la lógica individualista que dificulta la posibilidad de construir solidaridades colectivas); y la ley del embudo (toda situación pasa por el mismo filtro facilitando un control verticalista). Estas leyes producen una forma de hacer política y una forma de relacionamiento social que impactan tanto en el poder público y político, como en el militar, económico y/o familiar, y constituyen una dimensión cultural que penetra el inconsciente colectivo y en los imaginarios sociales; están enraizadas en la conciencia popular paraguaya y nos permiten comprender los efectos desmovilizadores que generan en el orden político (y más allá del mismo) desde la comprensión de una tradición cultural de larga duración.

Podemos preguntarnos jes la cultura política paraguaya uno de los principales obstáculos para la democratización? Suscribiendo al planteo de Arditi (1992), el autoritarismo no puede pensarse como una práctica circunscrita al gobierno o a lo político-partidario, sino que impregna todos los niveles capilares del tejido societal.

Pero de acuerdo a lo que ocurre en Paraguay podemos colegir que la ciudadanía manifiesta opiniones que no parecen apoyarse en supuestos democráticos, sino autoritarios. Esos supuestos precisamente, son los de la imposibilidad de la alternancia democrática en el poder y, en el caso de ocurrir un cambio de partido, se espera que sobrevenga en un contexto de ruptura institucional (Brugnoni, 2007, p. 54).

Brugnoni (2007) retoma un informe de Latinobarómetro del año 2006, donde señala que el descreimiento en la democracia en Paraguay es el más alta en América Latina. Para el autor, uno de los datos llamativos es que la ciudadanía, pese al descreimiento y la desconfianza, no ha optado por un cambio del partido gobernante: "Esa ciudadanía que deja de confiar en la democracia no ha optado en todos estos años en utilizar el procedimiento democrático más natural de demostrar el descontento, como es la alternancia en el poder" (p. 53). Sin embargo, la crisis política abre un ciclo descendente de la participación electoral, evidenciando un proceso de "ajenidad del electorado hacia la política local" (Soler, 2012). A la luz de las conclusiones, es interesante observar que la alternancia se produce recién en el 2008 con el triunfo de Fernando Lugo, experiencia que no casualmente fue interrumpida.

Retomando el estudio de Brugnoni (2007), es la incredulidad respecto a la posibilidad de un cambio real la que conduce al ciudadano a tener una posición crítica con el sistema democrático en su conjunto, sin focalizar en el partido que gobierna. Desde esta perspectiva, el régimen democrático demuestra una mayor estabilidad frente a los gobiernos autoritarios porque el descontento se dirige primero al gobierno y, en última instancia, al régimen político: es decir, el descontento se dirige contra el partido gobernante y se clama por su desplazamiento. En los regímenes autoritarios en cambio, no se contempla la alternancia y el descontento se canaliza hacia el cambio del régimen político, es decir, hacia las reivindicaciones democráticas. 
En este sentido, podemos advertir que el límite a la reelección presidencial es solo un síntoma de la debilidad que expone el sistema político paraguayo, y que es necesario naufragar en temporalidades que nos lleven un poco más allá. La resistencia a la reelección no puede explicarse sin el stronismo, como así tampoco la no alternancia partidaria puede explicarse sin remitirnos a una cultura política que solo puede fundamentarse desde una mirada de larga duración.

\section{El Juicio político y el neogolpismo en Paraguay}

Otro elemento que introduce la reforma de la Constitución, con objetivos similares al planteado en el artículo anterior, es el juicio político (artículo 225):

El Presidente de la República, el Vicepresidente, los Ministros del Poder Ejecutivo, los Ministros de la Corte Suprema de Justicia, el Fiscal General del Estado, el Defensor del Pueblo, el Contralor General de la República, el Subcontralor y los integrantes del Tribunal Superior de Justicia Electoral, sólo podrán ser sometidos a juicio político por mal desempeño de sus funciones, por delitos cometidos en el ejercicio de sus cargos o por delitos comunes.

En Paraguay se aplicó en cuatro oportunidades. El primer caso, fue el de Raúl Cubas Grau (1999) tras el asesinato del por entonces vicepresidente de la nación Luis María Argaña (23 de marzo) que desencadenó una ola de manifestaciones y protestas conocida como la "masacre del marzo paraguayo". El ataque pergeñado contra el mandatario expuso la crisis política y social que atravesaba Paraguay, como así también las contradicciones en el seno del bloque dominante. La represión y las muertes en el marco de aquellas jornadas llevó a la Cámara de Diputados a presentar el pedido de juicio político contra el presidente Cubas Grau ante la Cámara de Senadores por "hechos que constituyen la causal de mal desempeño y que, además, podrían constituir delitos cometidos en el ejercicio del cargo". Sin embargo, no pudo culminar dado que el presidente presentó antes su renuncia.

Otro caso fue el del presidente Luis González Macchi, que no prosperó dado que no logró la mayoría en la Cámara de Senadores. También podemos mencionar el caso de la Corte Suprema de Justicia, donde el pedido recayó sobre tres de sus miembros (2003).

El caso de Fernando Lugo (2012) fue, tal vez, uno de los hechos más arbitrarios acontecidos bajo el régimen democrático y en el marco de la institucionalidad democrática:

El denominado "juicio político" (contra Lugo) fue un acto manifiestamente arbitrario por su desconocimiento del ordenamiento jurídico y, por ende, contrario al Estado de derecho, realizado bajo el ropaje de las formas previstas en la Constitución para el juicio político. Por ello, bien puede ser calificado como un golpe de Estado parlamentario (Claude, 2012, p. 106).

El hecho desencadenante fue el caso Curuguaty donde, en el marco de un desalojo en una propiedad del dirigente del Partido Colorado Blas Riquelme, asesinaron a 12 campesinos y 5 policías. Ante estos sucesos, el Partido Colorado impulsó el juicio político contra el presidente que fue apoyado, entre otros, por el Partido Liberal Radical Auténtico (PLRA), otrora aliado al oficialismo en la Alianza Patriótica para el Cambio.

La acusación giró en torno de los siguientes elementos:

- La realización de un acto político en el Comando de Ingeniería de las Fuerzas Armadas en el marco de un encuentro de jóvenes socialistas realizado en el año 2009. Además del financiamiento con fondos públicos de dicho encuentro, se destacan las banderas y las alusiones políticas de las mismas como así también los discursos pronunciados, donde los presentes, entre ellos el Ministro de la Secretaría de Emergencia Nacional, instan a la "lucha de clases".

- El caso Nacunday, donde se acusa al presidente Fernando Lugo de "instigar" y "facilitar" la toma de tierras en dicha zona.

- La incapacidad para desarrollar una política de Estado que disminuya la inseguridad ciudadana. 
- La suscripción al Protocolo de Montevideo-Ushuaia II en el Mercosur considerado como un "atentado contra la soberanía de la República".

- La Matanza de Curuguaty, donde acusan al gobierno y en particular a Fernando Lugo, por "inoperancia, negligencia, ineptitud e improvisación”, situación que amerita una acusación ante la Cámara de Diputados por el "mal desempeño de funciones".

Lezcano Claude (2012) analiza la inconstitucionalidad del procedimiento indicando la inexistencia del mal desempeño de las funciones. Uno de los cargos más cuestionables es el referido al Protocolo de Montevideo, Ushuaia II: "Se trata éste de un acto jurídicamente inexistente. Al respecto, lo actuado por el Poder Ejecutivo está encuadrado dentro de sus atribuciones. Además, el protocolo aún no fue sometido a la consideración del Congreso" (p. 111). Por otro lado, destaca la violación del derecho a la defensa al no concederle al exmandatario el tiempo necesario para la preparación de la misma. Es menester contemplar que la notificación de la acusación se produjo el jueves 21 a las 19 horas siendo a las 12 horas del día siguiente la presentación de la defensa. El tiempo que le otorgaron para la presentación oral fue mínimo, como el plazo previsto para preparar los alegatos y exponerlos antes la Cámara de Senadores. Otra inconstitucionalidad señalada fue el rol de la Cámara de Senadores que en su carácter de Tribunal no estudió lo alegado por las partes debido a la inexistencia del debate al respecto.

Sin embargo, uno de los hechos más graves del proceso remite a las pruebas que sustentan los delitos imputados contra Fernando Lugo. En el libelo acusatorio los fiscales sostuvieron que "todas las causales mencionadas más arriba, son de pública notoriedad, motivo por el cual no necesitan ser probadas, conforme a nuestro ordenamiento jurídico vigente". Pese a esto, la acusación fue aprobada por la totalidad de la Cámara de Senadores.

El juicio político, pese a ser una figura constitucional, violó el debido proceso y el derecho a la defensa, vulnerado las garantías que ofrece el Estado de derecho. Conllevó a su vez una ruptura entre el Estado y los partidos respecto a la sociedad: la mayoría partidaria primó sobre la voluntad popular expresada electoralmente: "el presidente Fernando Lugo, electo por el voto libre y mayoritario de ochocientos mil paraguayos, fue destituido en un juicio sumario en menos de 23 hs por la voluntad de unas decenas de legisladores" (Camacho, 2012, p. 17).

Para Milda Rivarola (2012) la interrupción del gobierno de Lugo no fue un simple cambio de gobierno, fue la ruptura del contrato social: del contrato republicano y democrático de 1992 se retornó al contrato dictatorial. De esta manera, el juicio político no hizo más que enmascarar un golpe de Estado contra un gobierno democrático que venía a romper con décadas de permanencia del ANR-Partido Colorado en la dirección del gobierno.

Sin embargo, a diferencia de los golpes de Estado "clásicos", el golpe contra Lugo evidenció el uso de mecanismos de legitimación del orden constitucional (Carbone, 2012) basados en las reglas de la democracia estatuida durante el poststronismo - no hay ruptura, sino que prevalece la continuidad institucional-, pero violando y/o suspendiendo los derechos y las garantías constitucionales. Los golpes de Estado del siglo XXI, como los experimentados en Haití (2004), Honduras (2009), Paraguay (2012) y Brasil (2016), y aquellos que quedaron truncos, como en el caso de Venezuela (2002), Bolivia (2008) y Ecuador (2010), inauguran formatos destituyentes acordes al proceso de cambio promovido en la región a partir de los gobiernos postneoliberales, populares y/o progresistas.

A modo de síntesis podemos observar que de marzo de 1999 a junio de 2012 el juicio político fue utilizado en cuatro oportunidades:

La frecuencia promedio de alrededor de tres años en cuanto a su utilización efectiva, a lo cual deben sumarse las frecuentes perturbadoras amenazas de juicio político, revelan, por una parte, una vida político-institucional con sobresaltos y preocupaciones particularmente para el Ejecutivo y la Corte Suprema de Justicia, y, por la otra, una indebida preponderancia de las cámaras legislativas y de las clase política, en cuyos intereses y apetencias, por lo general, espurios, tienen su origen estos actos de inestabilidad (Lezcano Claude, 2012). 
$\mathrm{Al}$ igual que lo sucedido en los países mencionados, la forma que asume el neogolpismo, los actores, las instituciones y los procedimientos inauguran un nuevo ciclo de intervención en América Latina, donde se garantizan los mecanismos legales para dar continuidad al régimen democrático (Soler, 2014), consagrando democracias con más sombras que luces.

\section{EsTAdo de EXCEPción. Los Límites DE LA LEGALIDAD PARA LA DEMOCRACIA}

El surgimiento de sistemas autoritarios en América Latina entre 1960 y 1980 se tradujo en un proceso de militarización a través de la Doctrina de Seguridad Nacional (DSN) como sustento ideológico (García, 1991; Rivera, 2002) y conllevó a militarizar el concepto de Seguridad Interna (Buitrago, 2002). En el marco de la Guerra Fría, la hipótesis de un enfrentamiento entre el comunismo y el "mundo libre" trasladaba al interior de las naciones una guerra interna que operaba como justificación para la intervención militar, la reformulación integral del Estado, la refundación jurídica de la Nación y la eliminación de toda forma de oposición (Chirio, 2016). De esta manera, las "guerras sucias" se insertaban en una guerra de carácter global construyendo escenarios ante la amenaza de un "otro" y combinando una red represiva legal e ilegal impartidas desde el Estado (Calveiro, 2012).

La DSN establecía una concepción militar del Estado como así también de funcionamiento de la sociedad, y un proceso de militarización de las instituciones estatales ante la "amenaza" del enemigo interno. Una de las consecuencias jurídicas fue la implantación de los Estados de excepción que, so pretexto de garantizar la seguridad nacional, expidieron normas para penalizar la protesta social y socavar los derechos humanos.

En América Latina, el Estado de excepción fue declarado en distintos momentos históricos y con algunos cambios en sus nomenclaturas: estados de emergencia (Nicaragua, República Dominicana, Colombia, Chile, Ecuador, Perú, Venezuela y Cuba); estado de sitio (Honduras, República Dominicana, Brasil, Argentina, Bolivia, Chile, Perú); estado de guerra (Colombia y Cuba); estado de movilización para la guerra (Cuba); estado de defensa (Brasil); estado de excepción (Paraguay); estado de conmoción (Colombia y Venezuela); estado de asamblea (Chile); estado de urgencia (Panamá); estado de alarma (Venezuela); y estado de catástrofe (Chile) (Villabella Armengol, 2006). Las causales utilizadas variaban en cada uno de los casos, como así también los derechos que se legitimaba suspender (Villabella Armengol, 2006).

Tanto en el derecho internacional (Corte Interamericana de Derechos Humanos, Comité de Derechos Humanos de la ONU) como en el derecho interno, los estados admiten que, en situaciones de crisis, las autoridades pueden suspender el ejercicio de ciertos derechos con el fin de reestablecer la normalidad y la garantía de otros. Es decir, reconocen la posibilidad de suspenderlos con el argumento de resguardar el estado de derecho y la democracia. Desde la teoría jurídica se han realizado aportes contundentes en torno a la naturaleza de los estados de excepción, estableciendo normas y principios que los regulan (Despouy, 2010; O’Donnell, 1984; Vertiz, 2016; Dávalos Muirragui, 2008), como así también identificando “anomalías” o “desviaciones" en sus aplicaciones (Despouy, 2010).

En relación a nuestro caso, la reforma constitucional en Paraguay introduce el Estado de excepción (artículo 288) para remplazar al Estado de sitio, mecanismo al cual había apelado el stronismo a lo largo de 35 años, sin reglamentación alguna:

La excepcionalidad ha de ser entendida como opuesto a todo lo que sea ordinario o normal, pero ello no nos debe confundir y debemos ser capaces de reconocer que en la actualidad la crisis es algo consustancial al propio sistema. Es más, el derecho de excepción está actualmente reconocido en prácticamente todas las constituciones concretamente, el derecho de excepción constituye una garantía de la Constitución frente a situaciones de crisis (Vertiz, 2016, p. 186).

El Estado de excepción en la Constitución paraguaya supone una serie de condiciones y garantías constitucionales entre las que se destacan las siguientes: ${ }^{8}$ 
- En caso de conflicto armado internacional, formalmente declarado o no, o de grave conmoción interior que ponga en inminente peligro el imperio de esta Constitución o el funcionamiento regular de los órganos creados por ella, el Congreso o el Poder Ejecutivo podrán declarar el estado de excepción, en todo o en parte del territorio nacional, por un término de sesenta días como máximo. En el caso de que dicha declaración fuera efectuada por el Poder Ejecutivo, la medida deberá\# ser aprobada o rechazada por el Congreso dentro del plazo de cuarenta y ocho horas.

- Durante la vigencia del estado de excepción, el Poder Ejecutivo sólo podrá ordenar, por decreto y en cada caso, las siguientes medidas: la detención de las personas indiciadas de participar en algunos de esos hechos, el traslado de ellas de un punto a otro de la República, así como la prohibición o la restricción de reuniones públicas y manifestaciones.

- El estado de excepción no interrumpirá\# el funcionamiento de los poderes del Estado, la vigencia de esta Constitución ni, específicamente, el hábeas corpus.

Existen corrientes a favor y en contra del Estado de excepción. Por un lado, una acepción que lo considera como una institución pasible de ser usada para legitimar la discrecionalidad de quienes ejercen el poder y, por otro lado, como una forma de proteger los derechos humanos ante situaciones particulares e imprevistas (Dávalos Muirragui, 2008). Es decir, una mirada que lo considera como una contravención total y absoluta del estado de derecho y/o la que sostiene la modificación de ciertos mecanismos para su defensa en situaciones meramente extraordinarias.

Sin embargo, es necesario partir de la definición de Giorgio Agamben (2005) quien lo considera como el momento del derecho en el que se suspende, precisamente, el derecho para garantizar su continuidad e inclusive su existencia. $\mathrm{O}$, en otras palabras, como la forma legal de lo que no puede tener forma legal, porque es incluido en la legalidad a través de su exclusión. De esta manera, los estados de excepción suspenden toda legalidad dejando a los ciudadanos a merced de lo que denomina “poder desnudo". Sin embargo, hay posturas teóricas discrepantes que cuestionan la idea del estado de excepción como la negación de la ley dado que no permite dar cuenta de la coexistencia del mismo con cierto orden jurídico, por más ficcional que este sea (Crespo, 2017, p. 120).

En Paraguay, el Estado de excepción se ha declarado en distintas oportunidades. La primera vez, en el marco del levantamiento militar contra el gobierno de Luis González Macchi, promovido por sectores de las fuerzas ligadas al ex General Lino César Oviedo (2000). En esa oportunidad, el presidente lo sancionó vía decreto presidencial (N. ${ }^{\circ}$ 8.772) por treinta (30) días a "raíz de la confusión generalizada por los hechos ocurridos en el Primer Cuerpo del Ejército y en la Comandancia de la Policía Nacional, así como en otras dependencias de las Fuerzas Públicas". ${ }^{9}$

En julio del 2002 González Macchi lo aplicó nuevamente a través del decreto N. 17.870 por cinco (5) días por la supuesta detección de "actos preparatorios para la ejecución de hechos punibles contra la existencia del Estado" sostenida en una denuncia realizada por la Comandancia de la Policía Nacional en relación al cierre de rutas, atentados, actos violentos y cierre de vías de tránsito que tenían el propósito de "quebrantar la seguridad interna y el orden constitucional”. ${ }^{10}$ En esta ocasión se prohibieron las reuniones públicas y las manifestaciones. Sin embargo, lo acompañó con otro decreto presidencial (N. $\left.{ }^{\circ} 17.855\right)$ que dispuso la cooperación de las FFAA con la Policía Nacional en los asuntos internos, amparado en la Constitución Nacional y en la ley de Defensa Nacional y Seguridad Interna (Ley N. ${ }^{\circ}$ 1337/99). En ambos casos el estado de excepción se aplicó bajo el argumento de la amenaza o conmoción interna, pero puede evidenciarse un desplazamiento en los agentes que la producen.

Con el gobierno de Fernando Lugo se agudizaron los conflictos políticos y sociales. Surge el Ejército del Pueblo Paraguayo (EPP) y deviene en el objeto dilecto del accionar represivo de las fuerzas de seguridad del Estado. De acuerdo a los Wikileaks de 2009 a 2010 alrededor de 17 cables emanados de la Embajada de EEUU en Asunción hacen referencia al EPP. El primer cable data del mes de marzo del 2008 -a un mes 
de las elecciones presidenciales- e informa que el Partido Patria Libre (PPL) anuncia la creación del EPP (O’Donnell, 2014). Las caracterizaciones remiten desde un "grupo pequeño e inactivo" que no puede poner en riesgo la seguridad interna de un país y que se asemeja más a una "banda delictiva" que a una "vanguardia revolucionaria", a una guerrilla con vinculaciones con las FARC cuyo nivel de operaciones amerita la creación de un Destacamento Conjunto de Respuesta Rápida (fuerza "especial” paraguaya asesorada, entrenada y financiada por EEUU); o a un grupo terrorista con vinculación con el narcotráfico que no solo amenaza la seguridad interna de Paraguay sino también los objetivos de EEUU.

En este marco de profundización del conflicto social, el "Informe de Chokokue" de la CODEHUPY (2014) denunció un plan sistemático de ejecuciones contra organizaciones campesinas: en 25 años de gobiernos posdictatoriales (entre el 3 de febrero de 1989 y el 15 de agosto de 2013) fueron ejecutados y desaparecidos 115 dirigentes y miembros de organizaciones campesinas. La masacre de Curuguaty (2012) constituyó uno de los acontecimientos más graves en tiempos de democracia, no solo por la crisis que desató, y que conllevó a la interrupción democrática de un gobierno elegido soberanamente, sino porque constituyó una bisagra en materia de violación a los derechos humanos.

El informe señaló a su vez el endurecimiento de las normas penales: desde el año 2009 se elevaron las penas por "invasión" a la propiedad privada, y a partir del 2010 el cierre de una ruta en el marco de una protesta puede ser considerado como "acto de terrorismo". A su vez, destacó y denunció la profundización de las estrategias de criminalización de la protesta de los sectores campesinos en Paraguay en el marco de un problema estructural, histórico e irresuelto por la tenencia de la tierra. La criminalización del campesino persigue objetivos políticos y económicos claros, en una articulación que integra a los dueños de la tierra, las corporaciones ligadas al agronegocio y los líderes políticos tradicionales, que utilizan al Estado como medio para lograr sus intereses (2014).

Bajo el gobierno de Fernando Lugo el estado de excepción se declaró en dos oportunidades a través del Congreso de la Nación. En el año 2010 a través de la Ley N. 3.994 se declaró por treinta (30) días en las localidades de Concepción, San Pedro, Amambay, Alto Paraguay y Presidente Hayes por la "grave conmoción interior generados por los grupos criminales” y autorizó al Poder Ejecutivo a disponer del empleo de la Fuerza Pública, Fuerzas Armadas de la Nación y la Policía Nacional. La segunda vez fue por sesenta (60) días (en octubre de 2011) para los departamentos de Concepción y San Pedro en base a la Ley N. 4473 por la "grave conmoción interior generada por grupos criminales".

La declaración del Estado de excepción (salvo en el caso del levantamiento militar contra el gobierno de González Macchi), además de ser un mecanismo avalado por la Constitución, se sostiene en la Ley N. 1377 de Defensa Nacional y Seguridad Interna sancionada en 1999 que autoriza el uso de las Fuerzas Armadas para la preservación o restablecimiento de la Seguridad Interna.

Sin embargo, las reformas legislativas impulsadas por el gobierno de Horacio Cartes (2013) recayeron prioritariamente sobre la política de seguridad interna y, a partir de los cambios introducidos, se habilitó la intervención de las FFAA sin sujeción a los preceptos que regulan el Estado de excepción y sin declaración formal del mismo (Pérez, 2014). De esta manera, en casos considerados como una "amenaza" para el orden interno, el presidente puede declarar la intervención de las FFAA sin necesidad de pasar por las exigencias constitucionales del Estado de excepción. Por lo tanto, si se declaraba en una situación de "anormalidad" y de forma "temporal", con las modificaciones introducidas los preceptos constitucionales pueden estar suspendidos permitiendo la intervención de las FFAA sin sujeción a las leyes limitativas del ejercicio del poder. 


\section{REFLEXIONES PRELIMINARES}

Tal como expresamos al inicio de este artículo, los acontecimientos acaecidos en marzo de 2017 ante la oposición de vastos sectores a la reelección presidencial, expusieron la naturaleza de la situación política que atraviesa Paraguay desde el derrocamiento del régimen autoritario de Alfredo Stroessner.

La transición a la democracia ha enfrentado múltiples problemas y complejidades desde su misma génesis: la preminencia del Partido Colorado y la inexistencia de la alternancia en el gobierno; los vestigios de una cultura política autoritaria -que, como observamos, solo puede comprenderse desde larga duración-; sumado a la construcción de una nueva legalidad nacida a la luz de la reforma constitucional de 1992.

A partir de las variables analíticas expuestas en este artículo (la reelección, el juicio político y el estado de excepción) pudimos analizar el proceso de construcción de una nueva legalidad y de un marco normativo que terminó condicionando y limitando el proceso de consolidación de la democracia. La prohibición de la reelección no cuestionó la no alternancia en la dirección del gobierno del Partido Colorado y, cuando la misma se produjo, se llevó a cabo un juicio político que se tradujo en golpe de estado que obturó dicha posibilidad histórica. De esta manera el golpe, pese a intentar revestirlo de institucionalidad, interrumpió un prematuro proceso de apertura política. Por otro lado, el estado de excepción como figura jurídica pasible de ser aplicado en situaciones extraordinarias so pretexto de una amenaza que ponga en riesgo el estado, la democracia y sus instituciones, fue utilizado como mecanismo legitimador de la política de seguridad interna vulnerando los estamentos propios del estado de derecho.

De esta manera, así como el régimen de Alfredo Stroessner apeló a la legalidad como instrumento de legitimación del régimen, el tránsito a la democracia inauguró un nuevo capítulo que acabó poniendo más límites a un proceso de por sí débil. Con las herramientas propias de la legalidad democrática se socava el estado de derecho, y la excepción y la emergencia coexisten y conviven con la normalidad.

En este sentido, arribamos a ciertas reflexiones preliminares que, lejos de clausurar debates, los abre, y necesariamente nos lleva a interrogarnos sobre la naturaleza de la democracia en América Latina y en Paraguay en particular, sobre las continuidades y rupturas respecto a los regímenes autoritarios, y a los desafíos que enfrentan. Y enfrentamos.

\section{Bibliografía}

Abente Brun, D. (1993). Paraguay en transición. Caracas: Editorial Nueva Sociedad.

Agamben. G. (2005). El Estado de excepción. Buenos Aires: Adriana Hidalgo Editora.

Ansaldi, W. y Giordano, V. (2012). América Latina, la construcción del orden. De las sociedades de masas a las sociedades en procesos de reestructuración. Volumen 2. Buenos Aires: Editorial Ariel.

Ansaldi, W. y Soler, L. (2015). Derechas en América Latina en el siglo XXI. En Carbone, R. y Soler, L. (eds.), Des-Cartes. Estampas de las derechas en Paraguay (pp. 15-26). Ciudad Autónoma de Buenos Aires: Punto de Encuentro.

Arditi, B. (1992). Adiós a Stroessner. La reconstrucción de la política en el Paraguay. Paraguay: Centro de Documentación y Estudios (CDE) y RP Ediciones.

Balbuena Pérez, D. (2014). Derechos fundamentales y organizaciones criminales: análisis crítico de la respuesta del legislador paraguayo ante la creciente amenaza del terrorismo. InDret, (2). Recuperado de http://www.pensam ientopenal.com.ar/system/files/2014/06/doctrina39058.pdf

Braudel, F. (1970). La Historia y las Ciencias Sociales. Madrid: Alianza Editorial.

Brugnoni, J. P. (2007). Paraguay y la alternancia inverosímil. Revista de Estudios Políticos Contemporáneos Nova Polis, 2(12), 49-61.

Buitrago, F. (2002). La Seguridad Nacional a la deriva: del frente nacional a la posguerra fría. México, DF: Alfaomega Grupo Editor. 
Calveiro, P. (2012). Violencias de Estado: La guerra antiterrorista y la guerra contra el crimen como medios de control global. Buenos Aires: Siglo Veintiuno Editores.

Camacho. E. (2012). El golpe parlamentario en Paraguay. Una aproximación jurídica. Asunción: Editorial Arandura.

Carbone, R. y Soler, L. (2012). Franquismo en Paraguay. El golpe. Buenos Aires: El 8vo Loco.

Carbone, R. y Soler, L. (2015). Des-Cartes. Estampas de las derechas en Paraguay. Ciudad Autónoma de Buenos Aires: Ed. Punto de Encuentro.

Claude, L. L. (2012). Historia Constitucional de Paraguay (período 1870-2012). Revista Jurídica Universidad Americana, 3, 173-291

Claude, L. L. (2012). Sobre el “juicio político" al presidente Fernando Lugo Méndez. En Camacho, E. (comp.), Golpe parlamentario en Paraguay. Una aproximación jurídica (pp. 105-123). Asunción: Editorial Arandura.

Chirio, M. (2016). Lutter contre l'ennemi interne: la longue histoire d'une obsession de la droite brésilienne. Revista Nuevo Mundo, Mundos Nuevos. Recuperado de https://nuevomundo.revues.org/68827?lang=pt

Comisión de Verdad y Justicia (2008). Informe final. Capitulo de conclusiones y recomendaciones sobre DDHH en Paraguay. Asunción: Comisión de Verdad y Justicia.

Coordinadora de Derechos Humanos del Paraguay (2014). Informe Chokokue 1989-2013. El plan sistemático de ejecuciones en la lucha por el territorio campesino. Asunción: Coordinadora de Derechos Humanos del Paraguay (CODEHUPY).

Crespo, M. V. (2017). Dictadura en América Latina. Nuevas aproximaciones teóricas y conceptuales. Centro de Investigación en Ciencias Sociales y Estudios Regionales / Universidad Autónoma del Estado de Morelos, Cuernavaca.

Dávalos Muirragui, M. D. (2008). Estados de excepción: ¿Mal necesario o herramienta mal utilizada? Una mirada desde el constitucionalismo contemporáneo. En Ramiro Ávila Santamaría (ed), Neoconstitucionalismo y Sociedad. Ministerio de Justicia y Derechos Humanos. Quito: V\&M Gráficas.

Despouy, L. (2010). Los derechos humanos y los estados de excepción. Buenos Aires: El Mono Armado.

Escobar, T. (2012). Los Golpes. Algunas consideraciones sobre la reciente ruptura del orden democrático. En Carbone, R. y Soler, L (eds.), Franquismo en Paraguay. El golpe. Buenos Aires: El 8vo Loco.

García, A. (1991). La doctrina de la seguridad nacional. Volumen 1 y 2. Buenos Aires: Centro Editor de América Latina.

Giordano, V. (2014) ¿Qué hay de nuevo en las nuevas derechas? Nueva Sociedad, 254, $46-56$.

Goizueta Vertiz, J. (2016). Los Estados de excepción en América Latina: los controles desde el derecho internacional. Revista Facultad de Derecho y Ciencias Politicas, 98, 183-215.

Laterza, R. G. (1989). Legitimidad y legalidad en el nuevo contexto político paraguayo. Revista Paraguaya de Sociología, vol. 131, 143-158.

Lezcano Claude, L. (2012). Historia Constitucional de Paraguay (período 1870-2012). Revista Jurídica Universidad Americana, 3, 173-291.

Lezcano Claude, L. (2012). Sobre el “juicio político” al presidente Fernando Lugo Méndez. En Camacho, E. (comp.), Golpe parlamentario en Paraguay. Una aproximación jurídica (pp. 105-123). Asunción: Editorial Arandura.

Lezcano, C. M. (1990). El régimen militar de Alfredo Stroessner: Fuerzas Armadas y Política en el Paraguay (1954-1989). Santiago de Chile: Comisión Sudamericana de Paz.

Lezcano, C. M. y Martini, C. (1994). Fuerzas Armadas y democracia. A la búsqueda del equilibrio perdido. Paraguay 1989-1993. Asunción: Centro de Documentación y Estudios (CDE).

Nickson, A. (2014). La Guerra Fría y el Paraguay. Asunción: Editorial El Lector.

O’Donnell, D. (1984). Legitimidad de los estados de excepción, a la luz de los instrumentos de derechos humanos. Derecho PUCP, 38, 165-231.

O’Donnell, S. (2014). PolitiLeaks. Todo lo que la politica argentina quiso esconder. Sus secretos en Wikileaks de la A a la Z. Buenos Aires: Sudamericana. 
Pérez, D. E. B. (2014). Derechos fundamentales y organizaciones criminales: análisis crítico de la respuesta del legislador paraguayo ante la creciente amenaza del terrorismo. InDret, (2). Recuperado de http://www.pensam ientopenal.com.ar/system/files/2014/06/doctrina39058.pdf

Quevedo, C. (2015). La construcción del (des)orden neoliberal. En Carbone, R. y Soler, L. (eds.), Des-Cartes. Estampas de las derechas en Paraguay (pp. 45-56). Ciudad Autónoma de Buenos Aires: Punto de Encuentro.

Quevedo, C. (30 de marzo de 2017). ¿Qué hay detrás del nuevo golpe parlamentario en Paraguay? Revista Zoom. Recuperado de https://revistazoom.com.ar/que-hay-detras-del-nuevo-golpe-parlamentario-en-paraguay/

Quevedo, C. y Soler, L. (2007). Imágenes de un incendio. La crisis de la enmienda en Paraguay. Cuadernos del Pensamiento Crítico Latinoamericano, 44.

Riquelme, M. (1992). Stronismo, golpe militar y apertura tutelada. Asunción, Paraguay: Centro de Documentación y Estudios (CDE).

Riquelme, M. (1993). Desde el stronismo hacia la democracia: el papel del actor militar. En Abente Brun, D. (eds.), Paraguay en transición. Caracas: Editorial Nueva Sociedad.

Rivarola, M. (2012). La recisión del contrato social. En Camacho, E. (comp.), Golpe parlamentario en Paraguay. Una aproximación jurídica (pp. 139-145). Asunción: Editorial Arandura.

Rivera, E. D. J. V. (2002). Historia de la Doctrina de Seguridad Nacional. Convergencia Revista de Ciencias Sociales, 9 (27). México DF: UNAM.

Rodríguez, J. C. (1991). Los laberintos de la obediencia. Paraguay 1954/1989. Nueva Sociedad, 12, 49-55.

Rouquié, A. (1984). L'état militaire en Amérique Latine. 2da edición. Buenos Aires: Emecé Editores.

Soler, L. (2009). Dominación política y legitimidad. El stronismo en el contexto de América Latina. Revista Nova Polis, 4. Recuperado de http://paraguay.sociales.uba.ar/files/2011/07/Soler_01.pdf

Soler, L. (2012). Paraguay. La larga invención del golpe. El stronismo y el orden politico paraguayo [1era ed.]. Buenos Aires: Imago Mundi.

Soler, L. (2014). Golpe de Estado y derechas en Paraguay. Transiciones circulares y restauración conservadora. Nueva Sociedad, Los rostros de la derecha en América Latina, 254, 73-83.

Soler, L. (3 de abril de 2017). La metáfora del Congreso en llamas. Página 12. Recuperado de https://www.pagina12 .com.ar/29485-la-metafora-del-congreso-en-llamas

Velásquez Rivera, E. de J. (2002). Historia de la Doctrina de Seguridad Nacional. Revista Convergencia, 9(27). México DF: UNAM.

Vertiz, J. G. (2016). Los Estados de excepción en América Latina: los controles desde el derecho internacional. Revista Facultad de Derecho y Ciencias Politicas, 98, 183-215

Villabella Armengol, C. (2006). Elecciones y Reforma del Estado en América Latina. Revista del Instituto de Ciencias Jurídicas de Puebla A.C., 18, 5-19.

\section{Notas}

1 Respecto al artículo 11, se modifica para que la mesa directiva se renueve entre 1 y el 30 de junio del año en curso en vez de hacerlo entre el 15 y el 30 de junio-. De igual manera, fue modificada la mayoría necesaria para aprobar las mociones de orden: se pasó de una mayoría de dos tercios (30) a mayoría absoluta (23). También se alteró el artículo 41 de tal manera de sustraer al presidente de la Cámara la atribución de obstruir las propuestas o comunicaciones que se presenten y que él considere improcedentes (Quevedo y Soler, 2017).

2 Disponible en: https://revistazoom.com.ar/que-hay-detras-del-nuevo-golpe-parlamentario-en-paraguay/

3 Disponible en: http://www.oas.org/es/cidh/prensa/comunicados/2017/042.asp

4 Disponible en: http://www.lanacion.com.py/destacado_edicion_impresa/2017/04/01/una-turba-atropello-e-incendi o-el-congreso/

5 Soler, L. (2017) "La metáfora del Congreso en llamas" Página 12, 3 de abril de 2017. Disponible en https://www.pag ina12.com.ar/29485-la-metafora-del-congreso-en-llamas

6 Disponible en: http://www.presidencia.gov.py/articulo/24885-mensaje-del-presidente-de-la-republica-horacio-cartes. html\#.WWkpkzNDlsM 
7 Disponible en: http://www.leyes.com.py/documentaciones/constitucion-nacional-paraguaya/partII_tituloII.php

8 Disponible en: http://www.mspbs.gov.py/dgaf-administracion/wp-content/uploads/2013/11/CN-Art-288.pdf

9 Recuperado de la Gaceta Oficial de la República de Paraguay http://www.gacetaoficial.gov.py/uploads/pdf/2009/2009-12-17/gaceta_2950_GKKJDBCGCHFCAIIFAAHIHFB BDABCFCJBCJAFKDAC.pdf

10 Recuperado de la Gaceta Oficial de la República de Paraguay http://www.gacetaoficial.gov.py/uploads/pdf/2009/2009-09-10/gaceta_2685_FBIAKHJFCAEDIBDAKHCIKJB DJFGBBDJGEHGEDEJF.pdf 